\title{
Correction to: GM6 Attenuates Alzheimer's Disease Pathology in APP Mice
}

\author{
Jin $\mathrm{Yu}^{1} \cdot$ Hong Zhu ${ }^{1}$ - Saeid Taheri ${ }^{1} \cdot$ William Mondy $^{1} \cdot$ Cheryl Kirstein $^{2} \cdot$ William R. Swindell $^{3}$ - Dorothy Ko ${ }^{4}$. \\ Mark S. Kindy ${ }^{1,2,5,6}$ (D)
}

Published online: 23 March 2019

(C) Springer Science+Business Media, LLC, part of Springer Nature 2019

\section{Correction to: Mol Neurobiol https://doi.org/10.1007/s12035-019-1517-2}

The original version of this article unfortunately contained a mistake.

The name of author "William Swindell" missed the midle initial "R.". This should be written as "William R. Swindell" as corrected above.

Publisher's Note Springer Nature remains neutral with regard to jurisdictional claims in published maps and institutional affiliations.

The online version of the original article can be found at https://doi.org/ 10.1007/s12035-019-1517-2

Mark S. Kindy

kindym@health.usf.edu

1 Department of Pharmaceutical Sciences, College of Pharmacy, University of South Florida, Tampa, FL, USA

2 Department of Psychology, College of Arts and Sciences, University of South Florida, Tampa, FL, USA

3 Heritage College of Osteopathic Medicine, Ohio University, Athens, OH, USA

4 Genervon Biopharmaceuticals, Montebello, CA, USA

5 James A. Haley Veterans Administration Medical Center, Tampa, FL, USA

6 Shriners Hospital for Children, Tampa, FL, USA 